\title{
MODELING AND ANALYSIS OF LATTICE TOWERS WITH MORE ACCURATE MODELS
}

\author{
Wenjiang Kang ${ }^{1}$, F. Albermani ${ }^{2}$, S. Kitipornchai ${ }^{1}$ and Heung-Fai Lam ${ }^{1, *}$ \\ ${ }^{1}$ Department of Building \& Construction, City University of Hong Kong, \\ Hong Kong Special Administrative Region, China \\ *(Corresponding author: E-mail: paullam@cityu.edu.hk) \\ ${ }^{2}$ Department of Civil Engineering, University of Queensland, Brisbane, Australia
}

Received: 26 May 2005; Revised: 3 February 2007; Accepted: 14 February 2007

\begin{abstract}
In traditional design, transmission towers are assumed to be trusses in the calculation of member axial forces, and secondary braces are usually neglected. However, this assumption does not accurately reflect the structural characteristics of transmission towers. This paper proposes a finite element model (FEM) in which member continuity, the asymmetrical sectional properties of members, the eccentricity of connections, and geometrical and material nonlinearities are considered. The proposed FEM is first verified using experimental results, and is then employed in the analysis of several lattice towers to investigate some of their practical aspects. Recommendations on the design of transmission tower systems are made according to the results of the analysis and given in the conclusion.
\end{abstract}

Keywords: Transmission towers, secondary bracing, nonlinear analysis, buckling, eccentric connections

\section{INTRODUCTION}

In conventional design, transmission towers are assumed to be trusses [1], and secondary braces are omitted from the analysis. The effects of secondary bracing, eccentric connections, member continuity, and asymmetric member section properties are indirectly considered by modifying a member's slenderness ratio. With the calculated axial force of the truss model, the member capacity is checked against the relevant column curves that are recommended in the design code, such as the BS standard [2] and the ASCE manual [3]. However, this practice makes the results of the analysis very uncertain. Cannon [4] invited a number of power companies and tower designers to predict the member axial forces and capacities for a typical transmission tower. The coefficients of variation (COVs) in the predicted axial forces of the braces and the main members by different participants were $18.0 \%$ and $9.3 \%$, respectively. Even for engineers, who followed the ASCE manual [3], the COV of the predicted capacities was $17.4 \%$. Cannon's statistics indicate that the predicted capacities of a given transmission tower by the traditional analysis and design method can vary significantly.

Many researchers have studied the factors that affect the accuracy of the truss model in the analysis [5-12]. In 1984, Roy et al. [7] investigated the effects of the secondary stresses that arise from joint rigidity and member continuity in the results of analysis. In 1986, Korol et al. [8] reviewed the importance of secondary stresses on the strength of trusses through experiments and parametric analysis. With the full-scale quadrant of a transmission tower panel, Knight and Santhakumar [10] found in 1993 that the effect of joints on the behavior of transmission towers is very great and that the secondary stresses are so significant that they may cause the failure of the leg members. This clearly indicates that the pin-connected truss model is inadequate to represent the real behavior of transmission towers. Robert et al. [12] showed in 2002 that the predicted ultimate strength of a transmission tower is more precise with the continuous beam model than it is with a truss model that was calibrated with full-scale test results. 
To design the load sequence of the full-scale transmission tower test and to find an alternative to the costly full-scale test, Kitipornchai et al. [5] and Albermani and Kitipornchai [6] developed a compact and practical nonlinear method to simulate the global structural response of transmission towers. The program that was developed, the AK-Tower $[5,6]$, has been employed to predict the behavior of many transmission towers, and its predicted results are in good agreement with the full-scale test results [6].

There is a strong need in the industry to study the behavior of lattice towers intensively. However, research has been directed toward the independent study of structural characteristics. This paper focuses on the development of a finite element model (FEM) that incorporates all of the structural characteristics of lattice towers, such as member continuity, asymmetric section properties, geometric and material nonlinearity, and eccentric connections. Experimental results from the work of Kitipornchai et al. [5] are employed to verify the proposed FEM, which is used with a typical transmission tower panel to study comprehensively the effects of several practical aspects of transmission towers. Design recommendations for these aspects are provided in the conclusion.

\section{THE FEM AND ITS VERIFICATION}

ANSYS, one of the most popular finite element analysis programs, was employed in the study that is reported herein. The BEAM189 element [13] was used to model the angle section. The BEAM189 element automatically provides section-relevant quantities at a number of sections along the structural member. To capture the nonlinearity of the section material, each section is assumed to be an assembly of a predetermined number of nine-node cells. Every angle member is divided into many elements along the longitudinal direction to capture precisely the deformation and to simulate the member's geometrical nonlinearity. The material nonlinearity of the steel angle section is simulated by the bi-linear model. The nodal degrees of freedom of the connecting members were coupled in specified directions to simulate the connection situations [13]. Furthermore, the connection eccentricity was modeled through the section offset command of ANSYS [13]. Note that the initial geometric imperfection was not included in the FEM.

To verify the proposed FEM, the experimentally measured ultimate loads of two angle trusses with different dimensions and member sections (trusses 1 and 2) in Kitipornchai et al. [5], as shown in Figure 1, were employed. Four configurations, which are denoted as 1-OS, 2-OS, 1-SS, and 2-SS, were considered, where 1 and 2 are the truss numbers, and OS (SS) indicates that the free edges of the angle web members are connected on the opposite (same) sides. The dimension L for trusses 1 and 2 is $1000 \mathrm{~mm}$ and $750 \mathrm{~mm}$, respectively. As all of the joints are fully welded, all of the connections are assumed to be rigid. Figure 1 shows the FEM of the original and failed trusses. As predicted by the FEM, the failure mode of these trusses was induced by the excessive bending of member 2, primarily in the plane that is perpendicular to the plane of the truss (as in Figure 2(b)), which agrees well with the experimental results in reference 5. TABLE 1 summarizes the calculated results of the proposed FEM and the experimental results [5]. The ultimate load results that were obtained with the proposed FEM were in reasonable agreement with the experimental results. The load-displacement curves of truss 2-OS are shown in Figure 3. The results in TABLE 1 and Figure 3 verify the capability of the proposed FEM. Because the practical yield stress is generally higher than the value that is prescribed by the steel grade, the ultimate load of the practical experiments is consistently higher than that which is predicted by the proposed FEM. The difference is relatively larger for the SS configuration, for which the ultimate loads are larger, than it is for the OS configuration. The small difference between the test and the FEM-predicted results, as shown in Figure 3, may also have been caused by such factors as material strength variance, residual stress, and imperfections, which were not considered in the proposed model. 


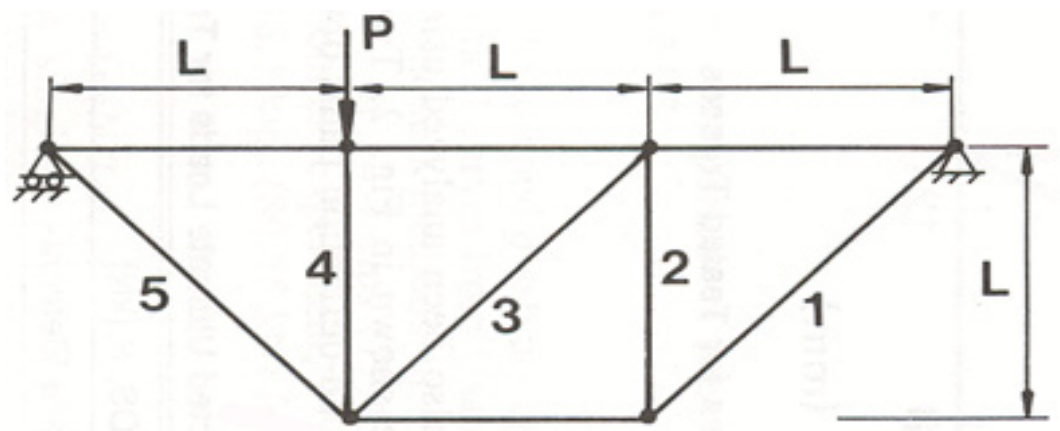

Figure 1. The Truss Experiment in Kitipornchai et al. [5]

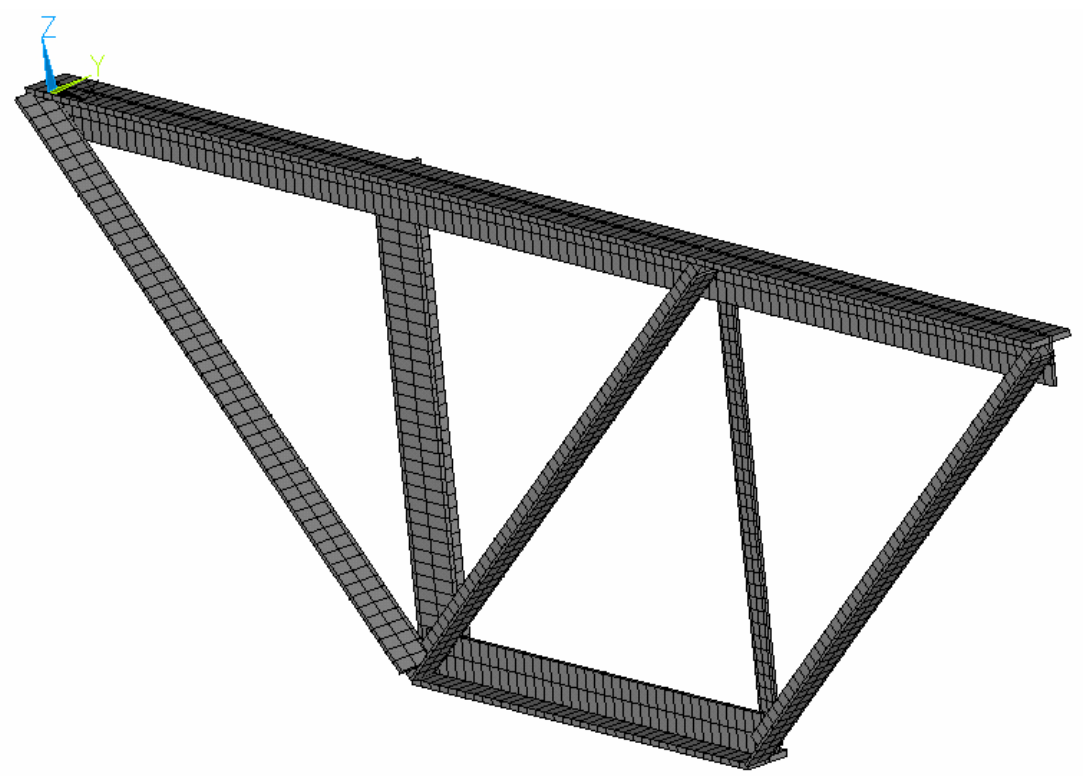

a) Original FEM

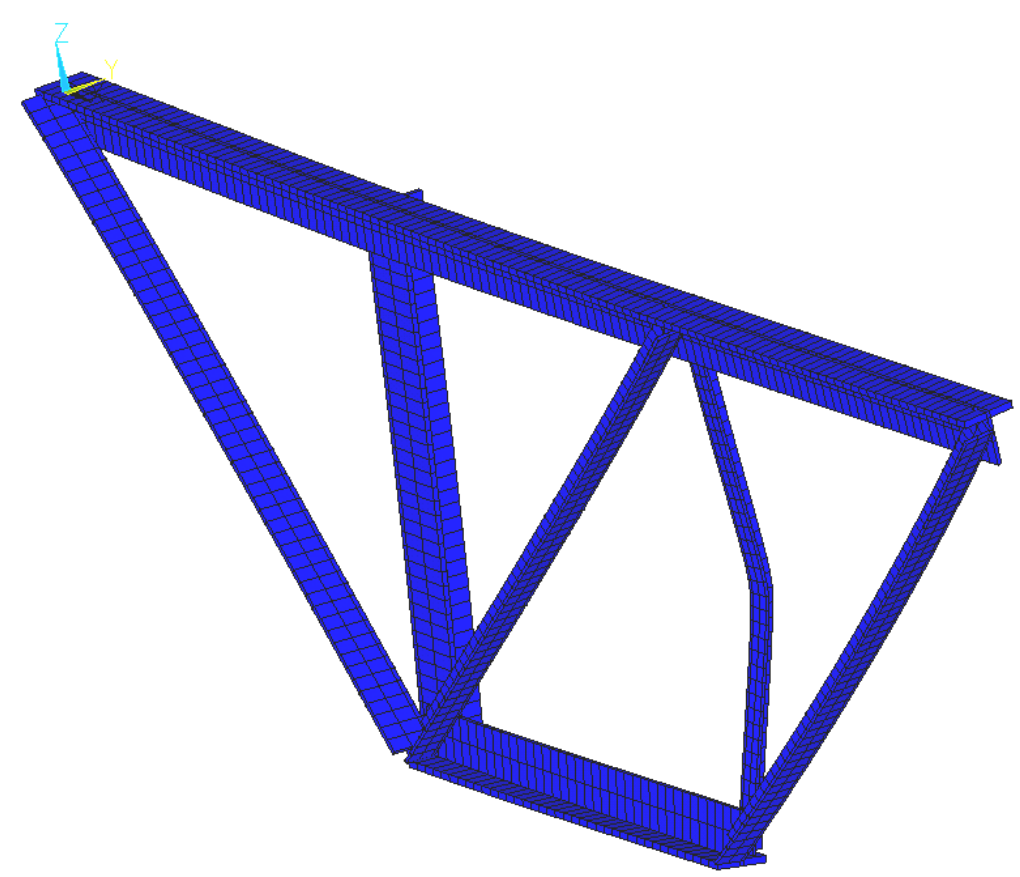

b) Failure Mode of the Truss (Predicted by the FEM)

Figure 2. Failure Mode of the Truss in the 2-OS Configuration, as Predicted by the FEM 
Table 1. Comparison of Test Results: Former and Current Analysis Results

\begin{tabular}{|c|c|c|c|c|c|}
\hline \multicolumn{2}{|c|}{ Truss No. } & 1-OS & 2-OS & 1-SS & 2-SS \\
\hline \multirow{2}{*}{$\begin{array}{c}\text { Ultimate } \\
\text { loads, P (kN) }\end{array}$} & Tests [5] & 84.4 & 134.1 & 139.5 & 167.2 \\
\cline { 2 - 6 } & $\begin{array}{c}\text { Proposed } \\
\text { FEM }\end{array}$ & 71.2 & 123.5 & 96.4 & 152.1 \\
\hline
\end{tabular}

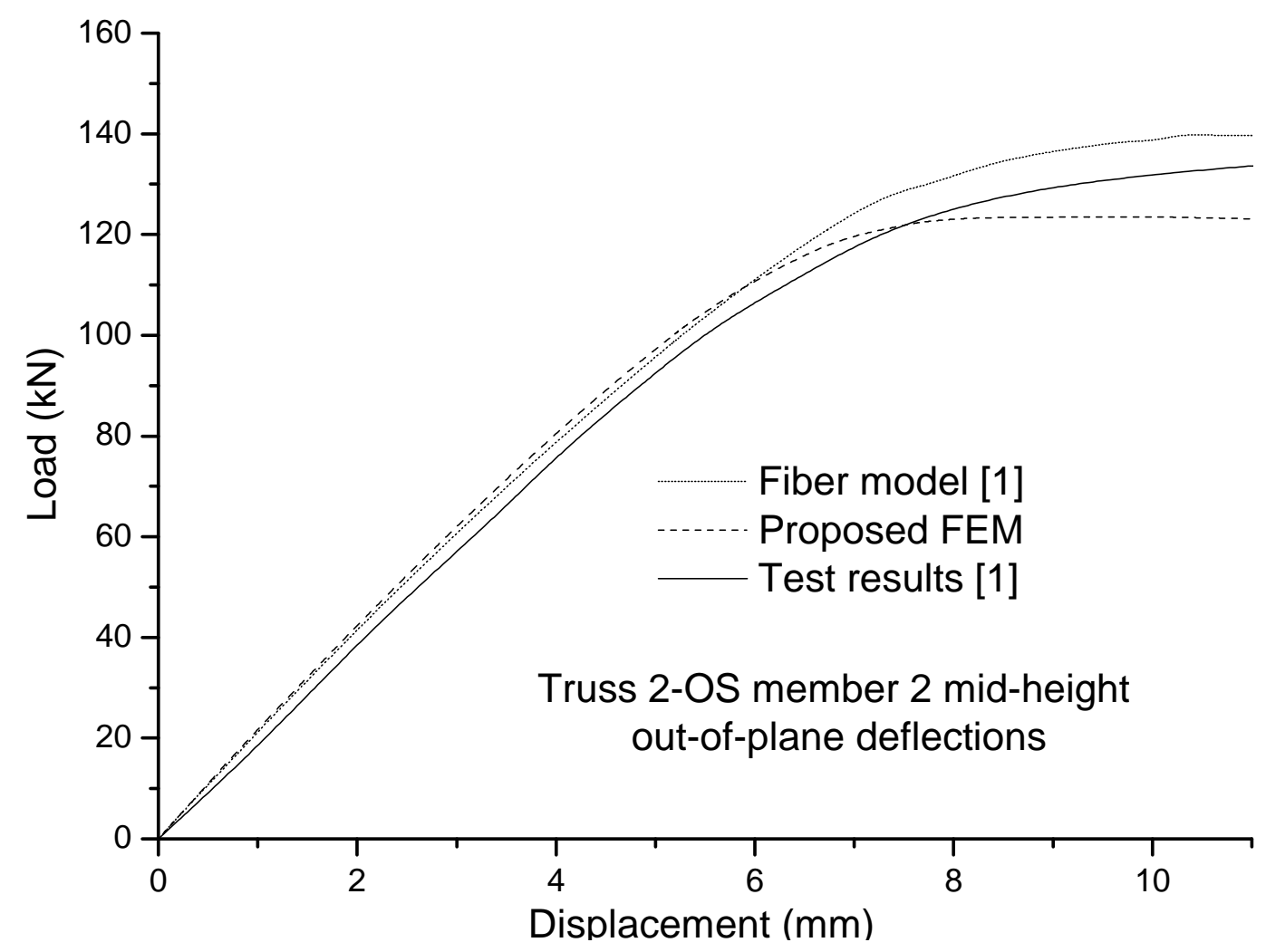

Figure 3. Comparison of Experimental and Theoretical Load-deflection Curves

\section{ANALYSIS RESULTS, COMPARISON AND DISCUSSION}

Figure 4 shows a typical transmission tower, which is employed as an example for analysis in this study. A typical leg of transmission towers is joined by a heavy splice to another large angle section (stub) that is embedded in the concrete foundation. As a result, the main leg can be modeled as a rigid support in the analysis. Figure 5 shows the physical and analytical models of a typical tower leg. 


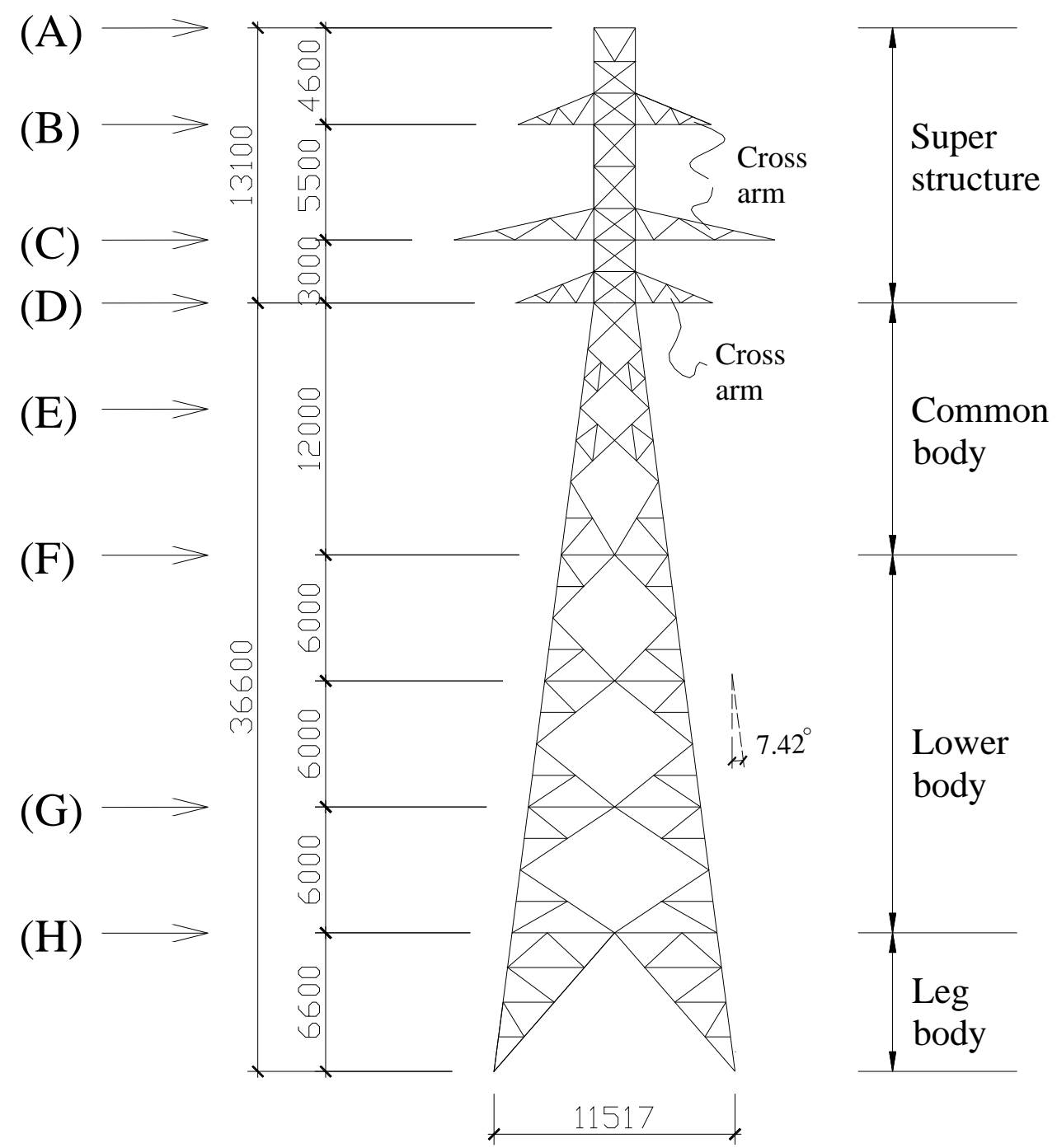

Figure 4. Full Geometric Model of a Transmission Tower

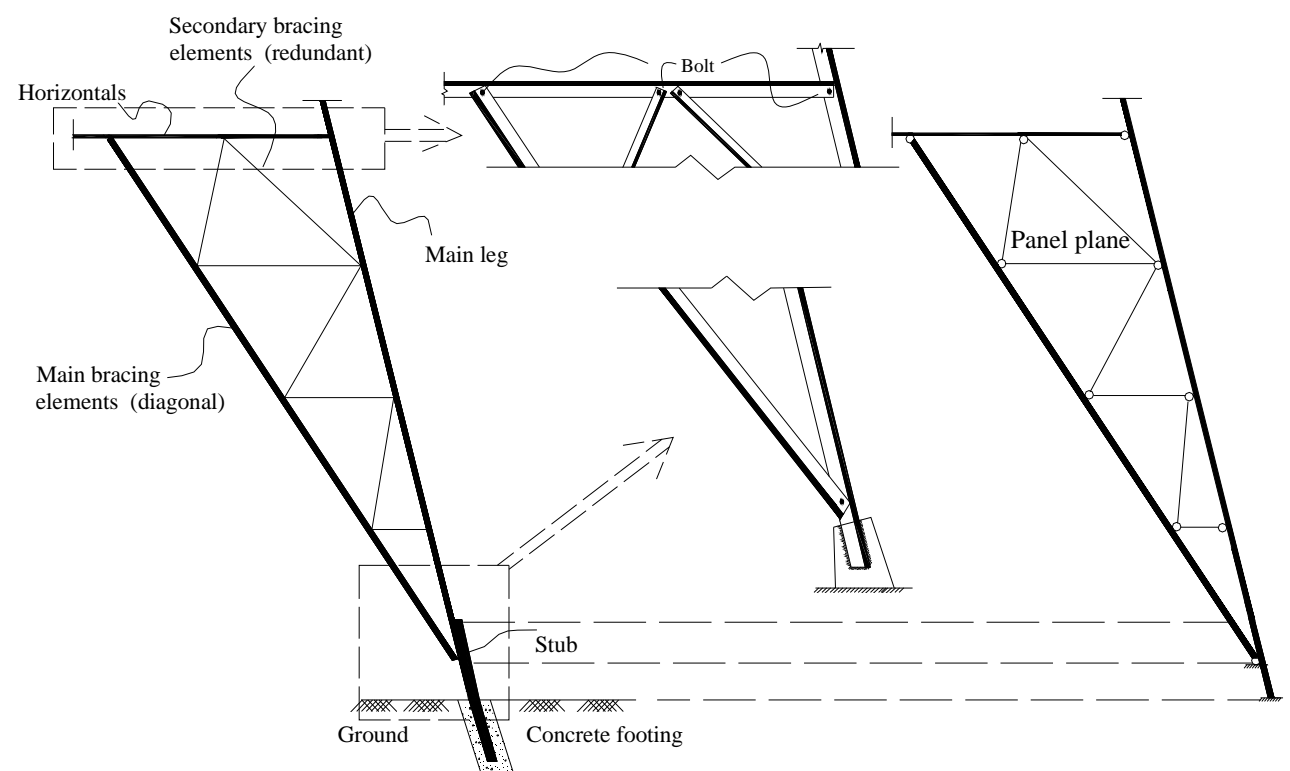

a) Physical Model

b) Analytical Model

Figure 5. Physical and Analytical Models for a Typical Transmission Tower Leg 
In general, each plane of a transmission tower is mainly employed to resist in-plane forces and moments. To make the comparison clear without sacrificing its representativeness, the current study focuses on the panel of a transmission tower, as shown in Figure 6. Furthermore, it is assumed that all of the structural members of the transmission tower are formed by angle sections. In the present model, L150 × $150 \times 16 \mathrm{~mm}, \mathrm{~L} 130 \times 130 \times 10 \mathrm{~mm}$, and L100 × $100 \times 6 \mathrm{~mm}$ sections are employed for the leg, horizontal, and diagonal members, respectively, and an L70 $\times 70 \times 5 \mathrm{~mm}$ section is used for the secondary braces.

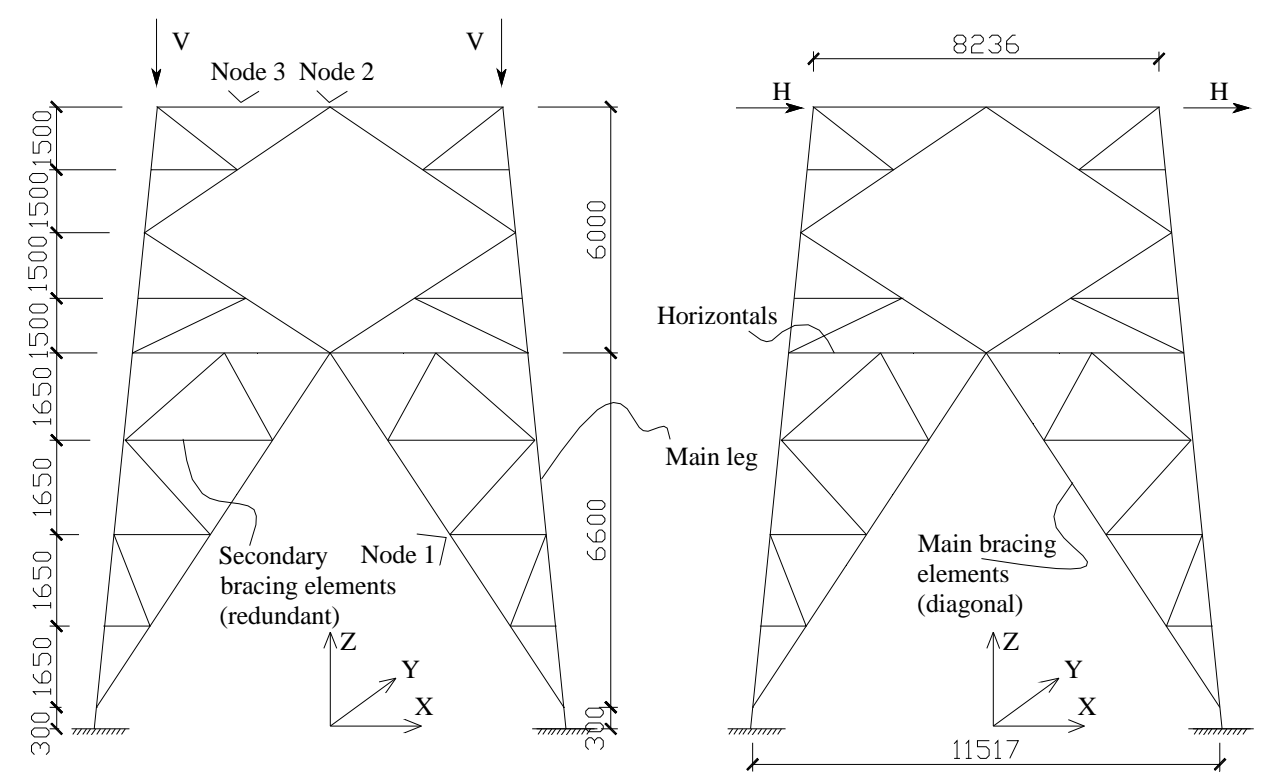

Figure 6. A Panel Model of the Body and Leg for Analysis

\subsection{Connection Details}

To incorporate the eccentric connection details in the model, all of the section properties of the connected angles are transformed to the connection axes. The connection axes for sections 1 and 2 are shown in Figures 7(a) and 7(c). The external loads are assumed to be applied along the corresponding contacting surfaces, as shown in Figure 7(b). Figure 7(d) shows the 3D view of the connection in the proposed FEM.

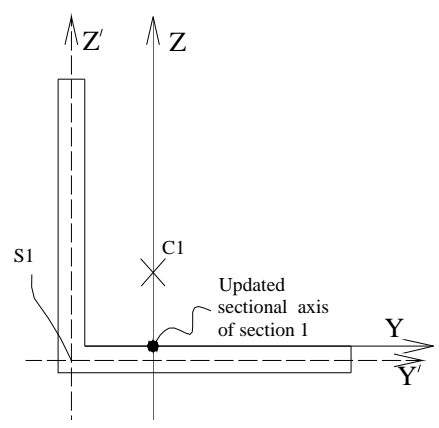

a) Offset of Section 1

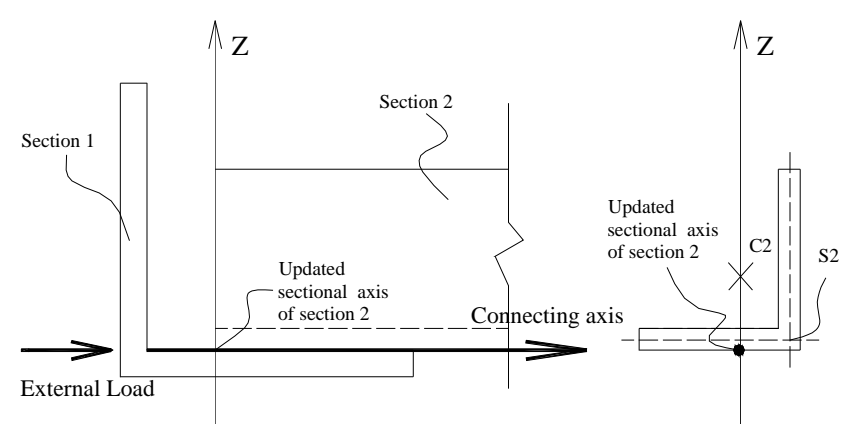

b) Connection Details

c) Offset of Section 2 


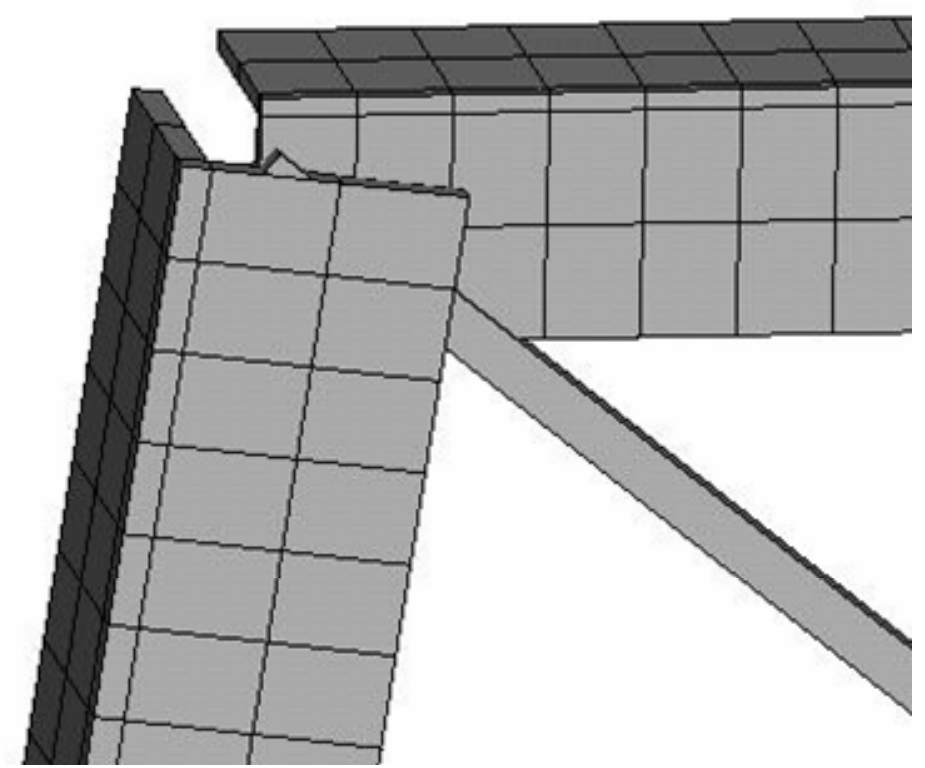

d) 3D View of a Typical Connection in the Proposed FEM

Figure 7. Modeling of Connections

\subsection{Effects of Connection Rigidity}

Three models are employed in this study to investigate the effects of the rigidity of brace end connections on the behavior of a transmission tower. In Model A, all of the main braces are assumed to be rigidly connected to the horizontals and the legs. In Model $\mathrm{B}$, the connections of the main braces are assumed to be in-plane pin-connected and out-of-plane rigid-connected. In Model $\mathrm{C}$, the connections of the main braces are assumed to be pinned in both in-plane and out-of-plane. In all three of the models, the secondary members are assumed to be pin-connected. The ultimate load and the load-displacement curves of the three cases are shown in Figures 8 and 9.

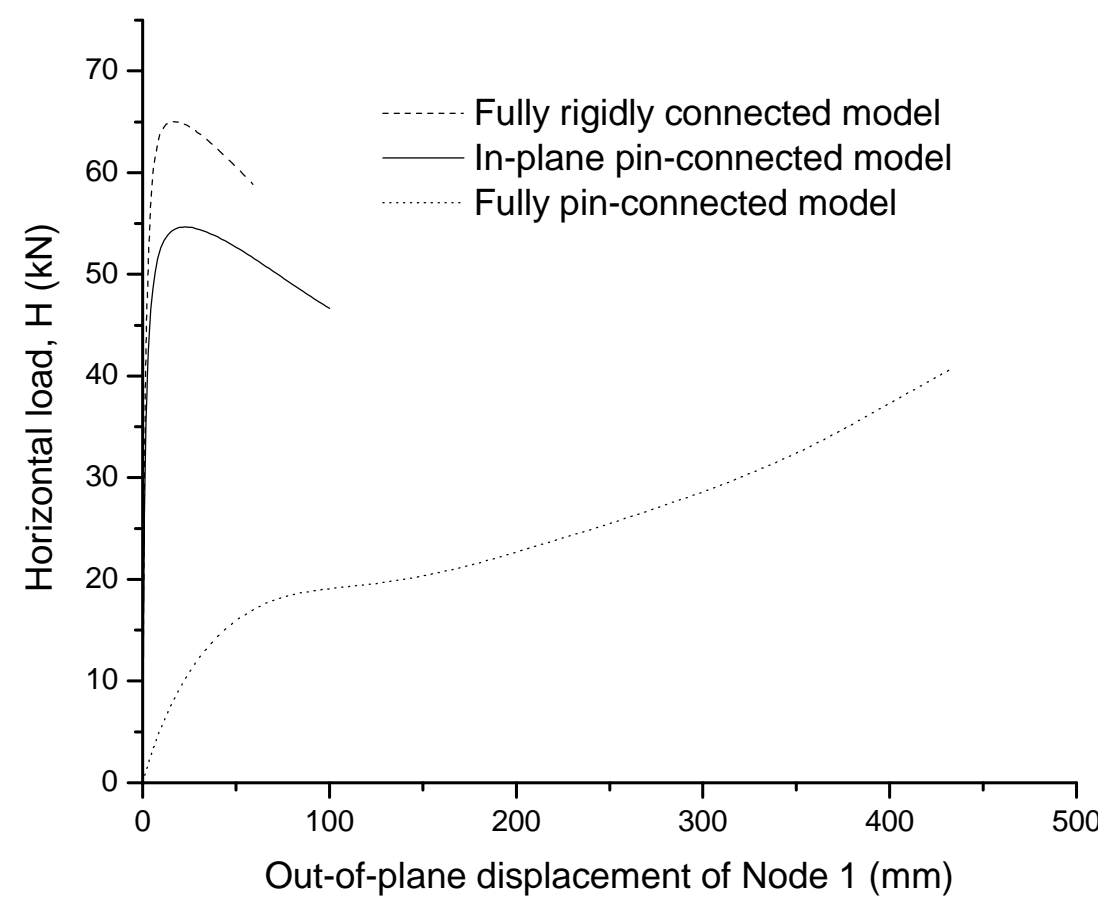

Figure 8. Load-deflection Curves of the Three Models under Horizontal Load 


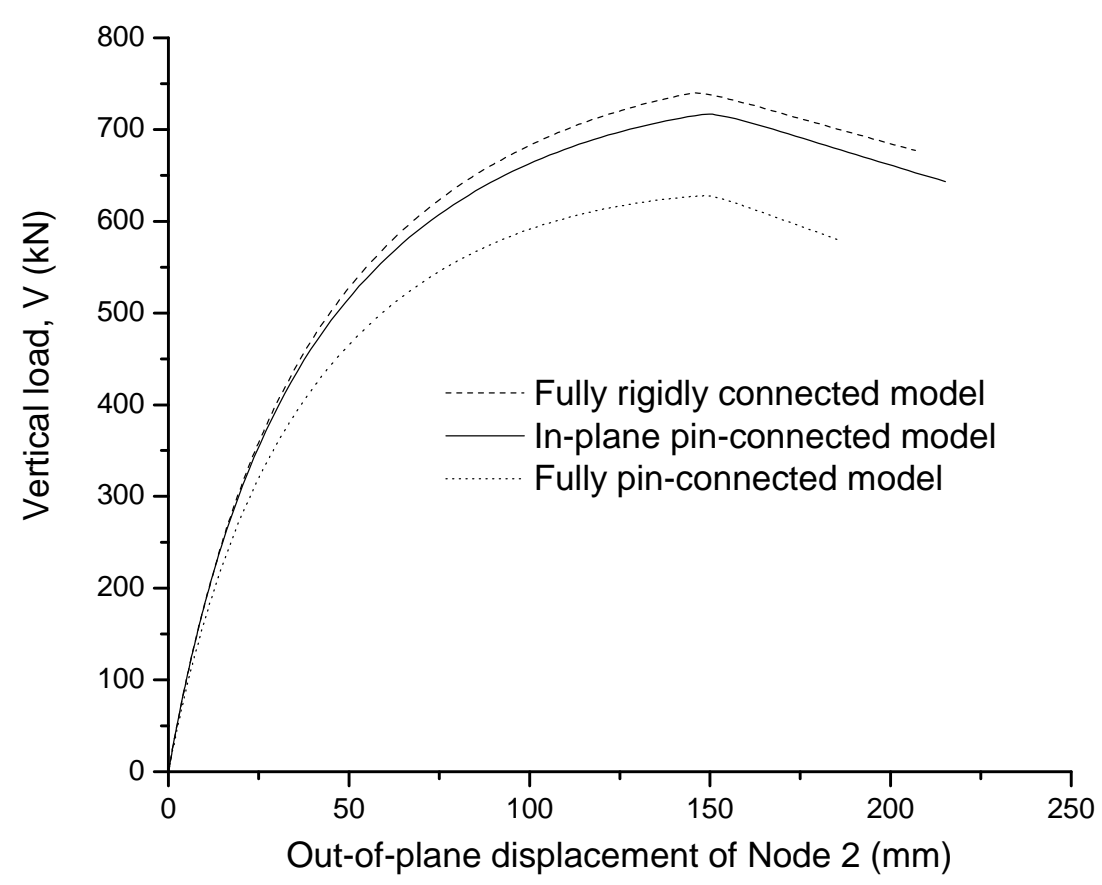

Figure 9. Load-deflection Curves of the Three Models under Vertical Load

Figure 8 shows that the connection rigidity has a considerable effect on the ultimate horizontal load capacity. Under the horizontal load, the ultimate load capacities of Models A, B, and C are 65.03 $\mathrm{kN}, 54.67 \mathrm{kN}$, and $40.67 \mathrm{kN}$, respectively. The ultimate load capacity of Model A (in which all of the main braces are rigidly connected) is $19 \%$ higher than that of Model B (which is in-plane pin-connected). Furthermore, the ultimate load capacity of Model A is 59.9\% higher than that of Model C (which is all pin connected). A similar trend can be observed in the vertical load case, as shown in

Figure 9.

The failure mode of Model A under horizontal load is shown in Figure 10. Model A fails due to the excessive bending of the main bracing member in the leg, primarily in the plane that is perpendicular to the plane of the truss. Model $\mathrm{C}$ also fails for the same reason, but at a much lower ultimate load. Model B has the intermediate ultimate load with a similar failure mode.

The failure modes of the three models under vertical load are similar, and one example is shown in Figure 11. Due to the difference in connection rigidity, the displacement curves and ultimate loads are different. 


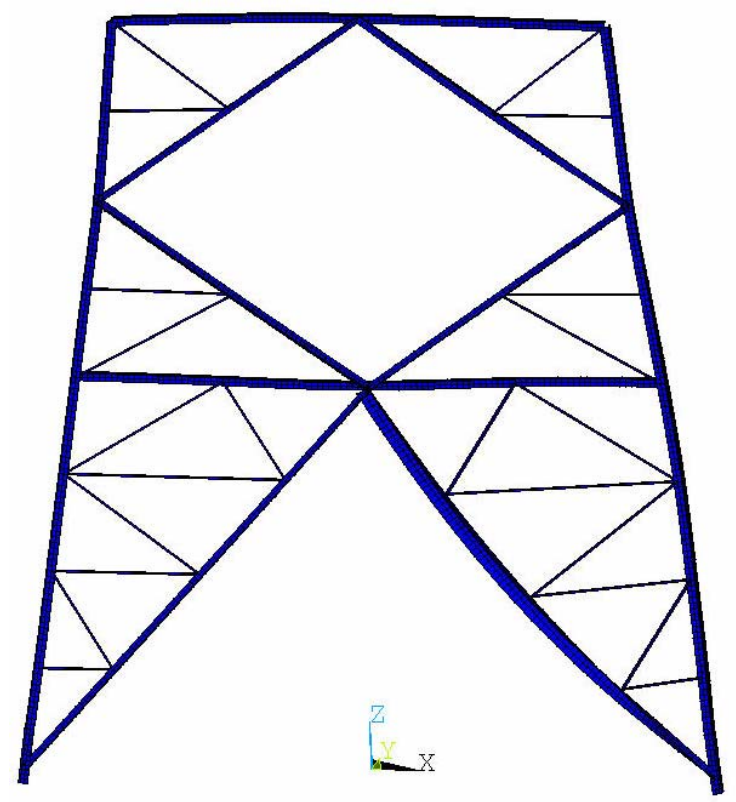

Figure 10. Failure Mode of Model A under Horizontal Load

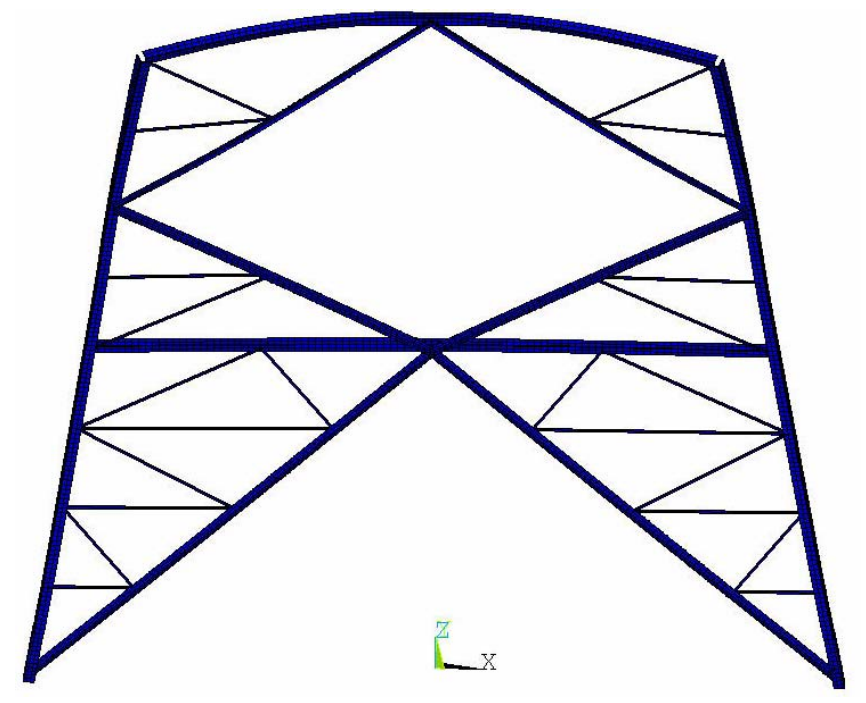

Figure 11. Failure Mode of Model A under Vertical Load

The above comparison shows that a rigid connection increases the buckling capacity, as was expected. In practice, the assumption of connection rigidity must be realistic; otherwise, we may either overestimate or underestimate the buckling capacity of the structure.

The effect of simultaneously applied horizontal and vertical load is also investigated. In the combined load case, the horizontal load $(\mathrm{H})$ and the vertical load $(\mathrm{V})$ are $30 \mathrm{kN}$ and $100 \mathrm{kN}$, respectively. The load factor versus the displacement curves is given in Figure 12. The failure mode of the tower under the combined load is illustrated in Figure 13. Under the combined load, the failure modes of the three models vary. However, the effect of the connection rigidity, which can be illustrated by a comparison of the corresponding ultimate loads in Figure 12, is the same as that which is indicated in Figure 8 and Figure 9, and therefore, only the vertical and horizontal load cases are considered in the following sub-sections. 


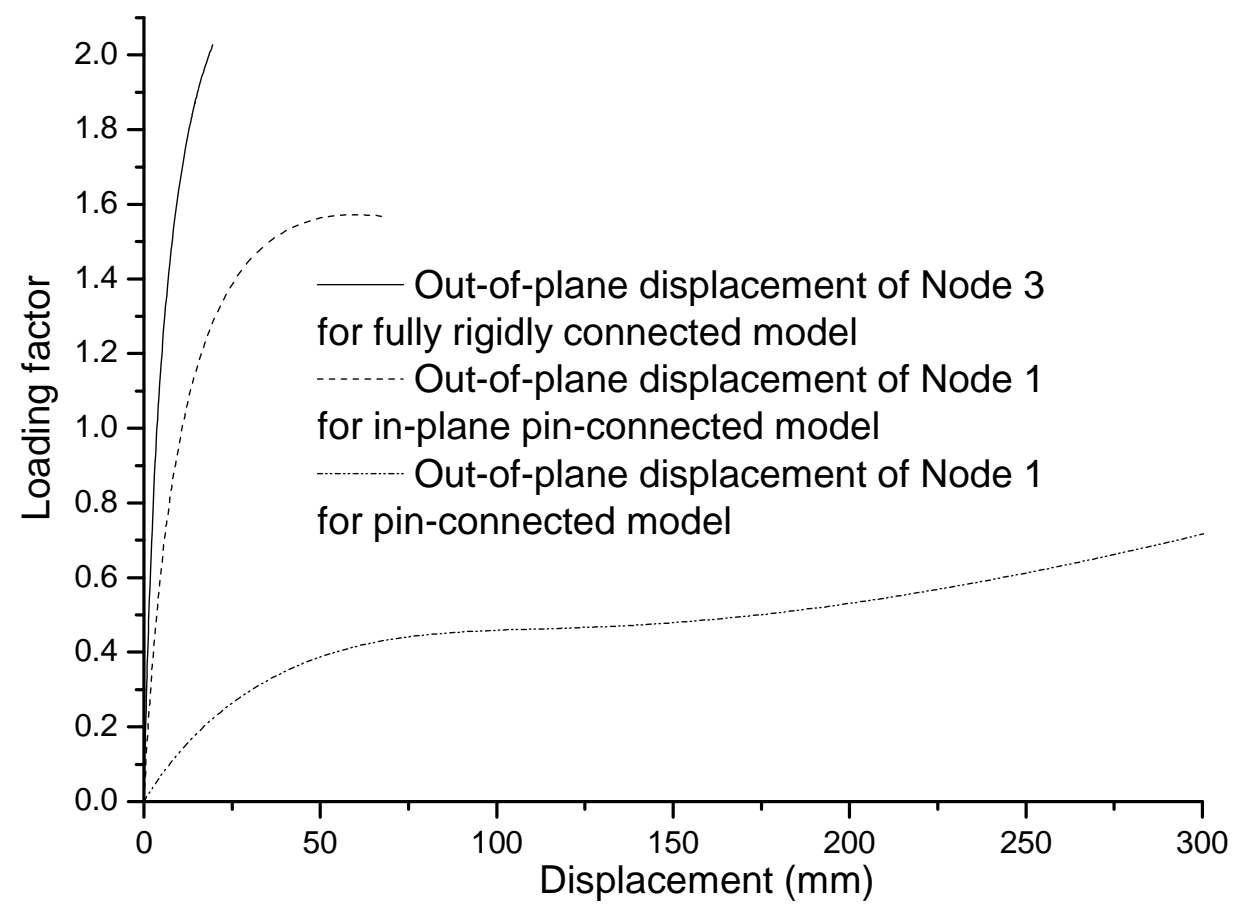

Figure 12. Load-deflection Curves of the Three Models under the Combined Load

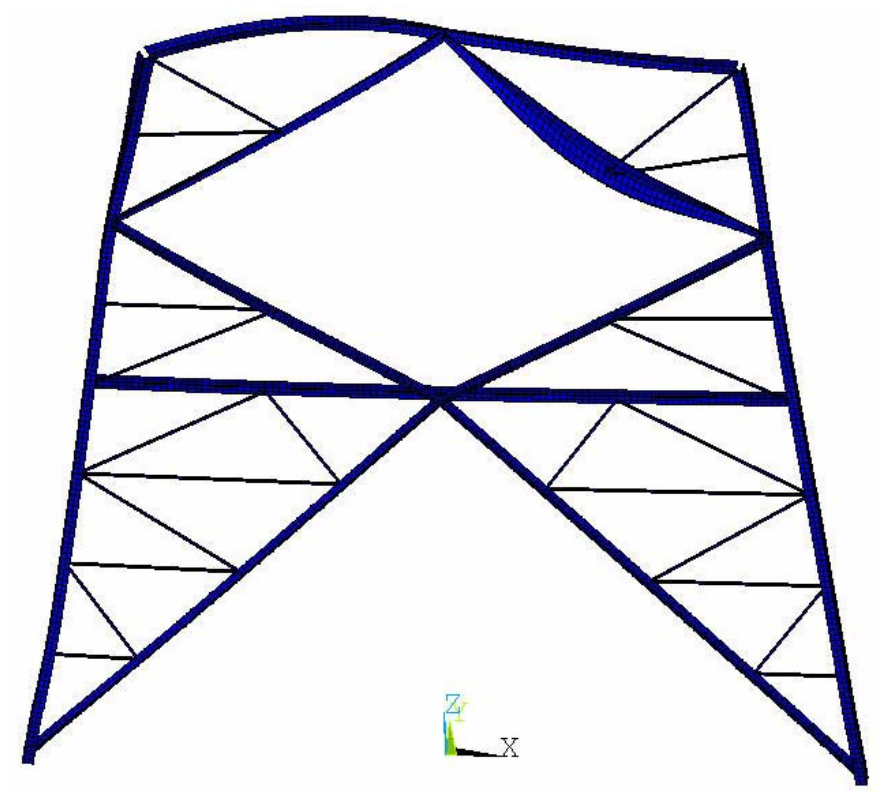

a) Failure Mode of Model A under the Combined Load 


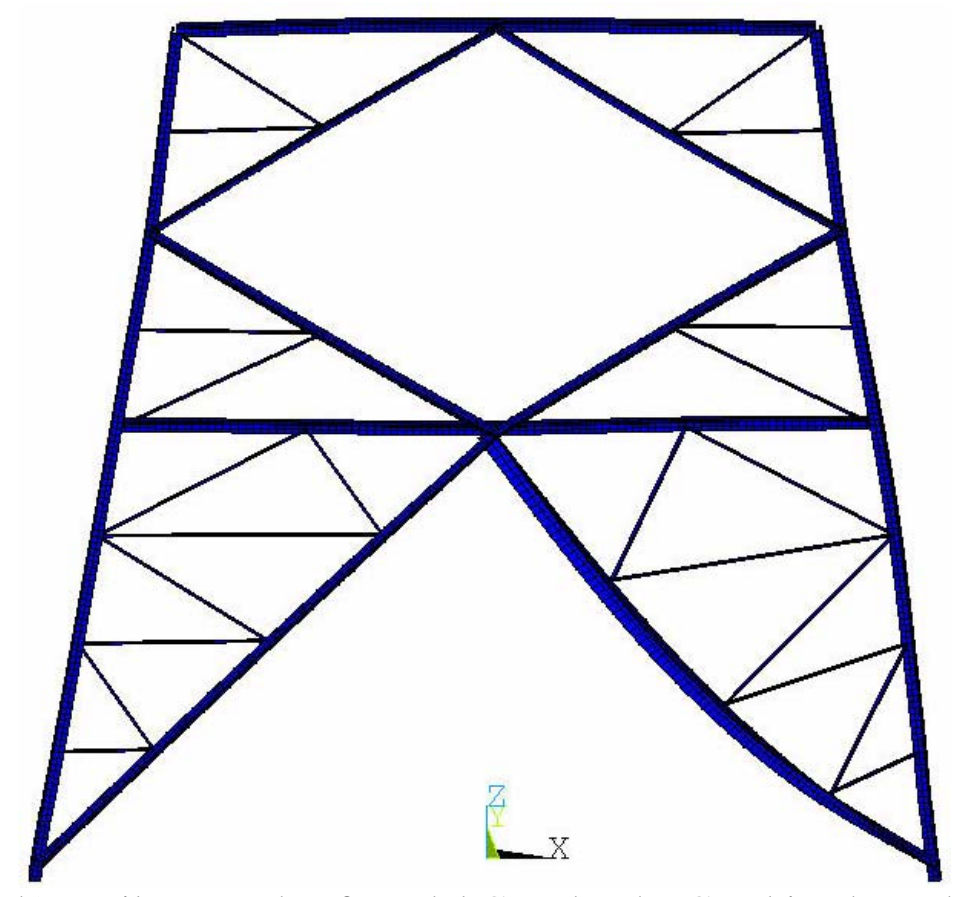

b) Failure Mode of Model C under the Combined Load

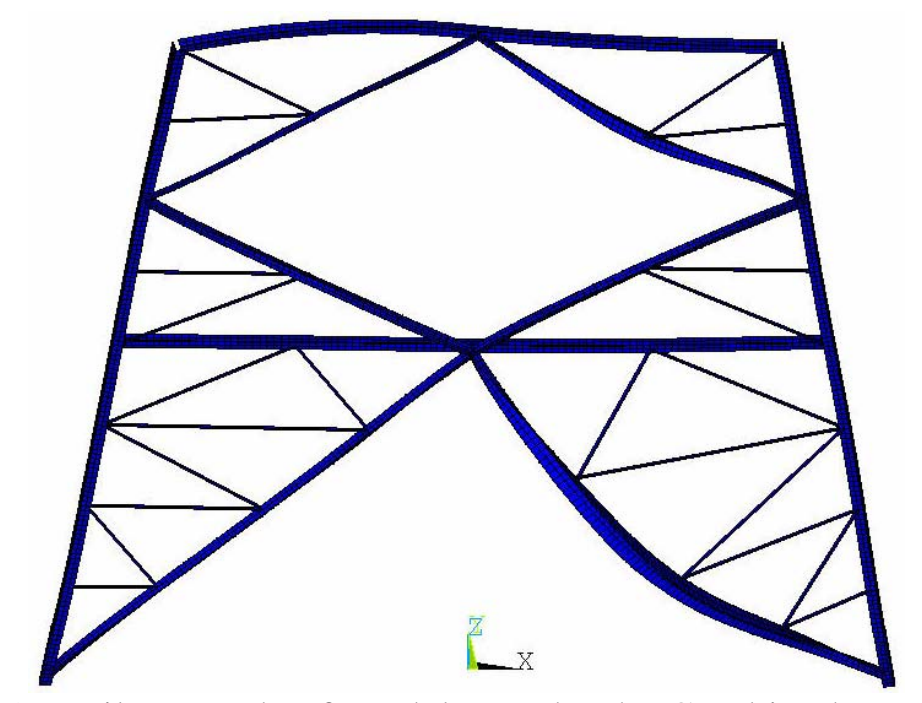

c) Failure Mode of Model B under the Combined Load

Figure 13. Failure Modes of the Three Models under the Combined Load

\subsection{Effect of Secondary Bracing and its Stress}

To study the effect of secondary braces, the two models that are shown in Figure 14 are employed. Secondary braces are considered in one model, but are neglected in the other. It turns out that the failure mode for the two models is the same. The load-displacement curves for the two models under horizontal and vertical loads are shown in Figures 15 and 16, respectively. 


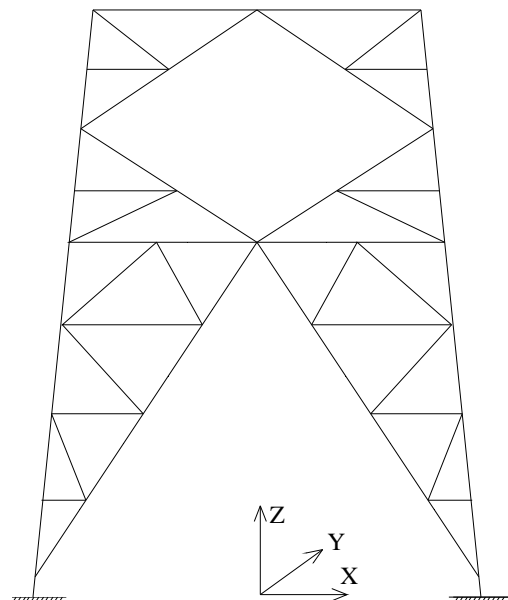

a) Model with Secondary Bracing

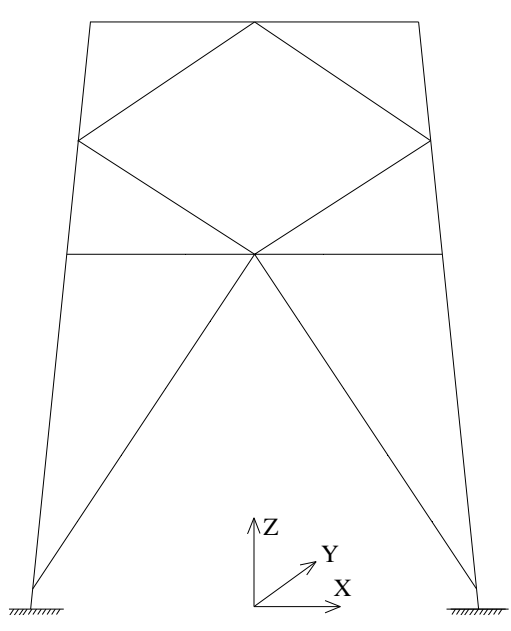

b) Model without Secondary Bracing

Figure 14. Analysis Models with and without Secondary Bracing

Figure 15 shows that the ultimate horizontal load capacity of the tower panel with secondary bracing is $65.03 \mathrm{kN}$, which is much larger than that of the tower panel without secondary bracing $(37.32 \mathrm{kN})$. A similar trend is observed in the vertical load case, which is shown in Figure 16, with an almost 50\% increase in ultimate load capacity.

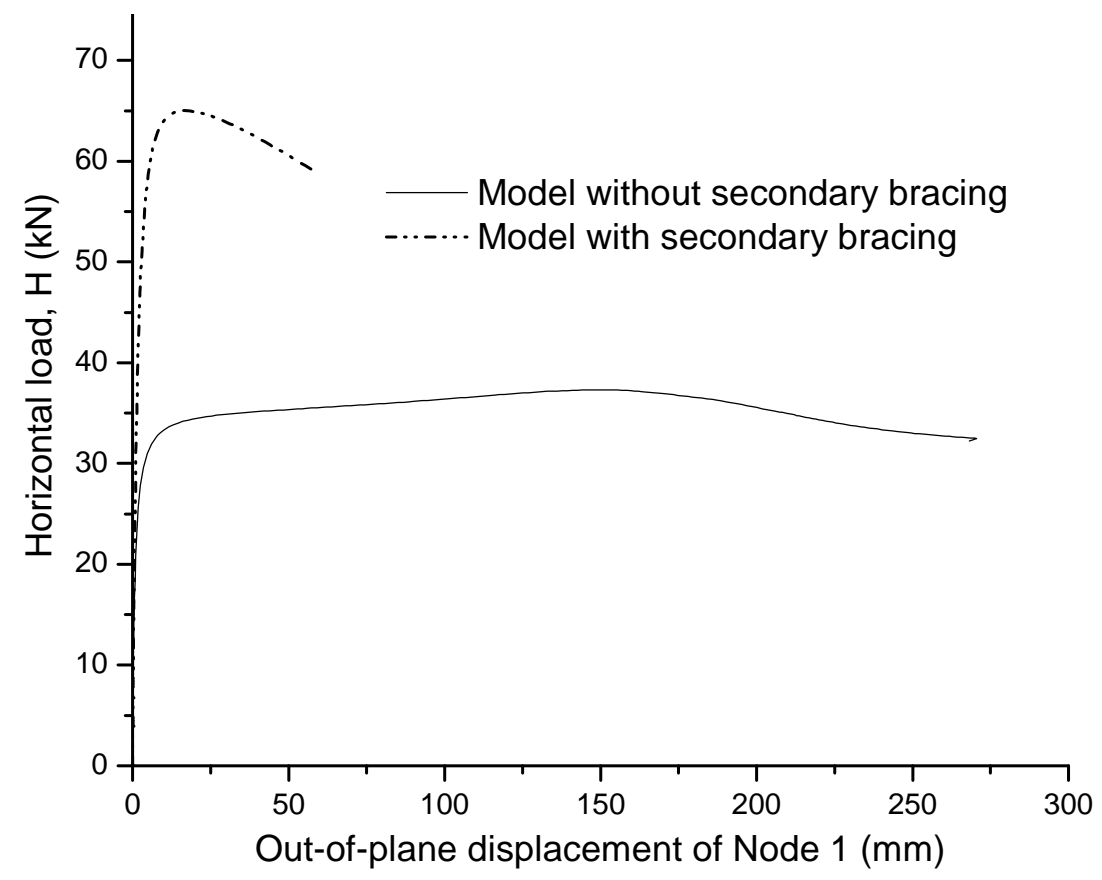

Figure 15. Load-deflection Curves of Rigid-connected Models under Horizontal Load 


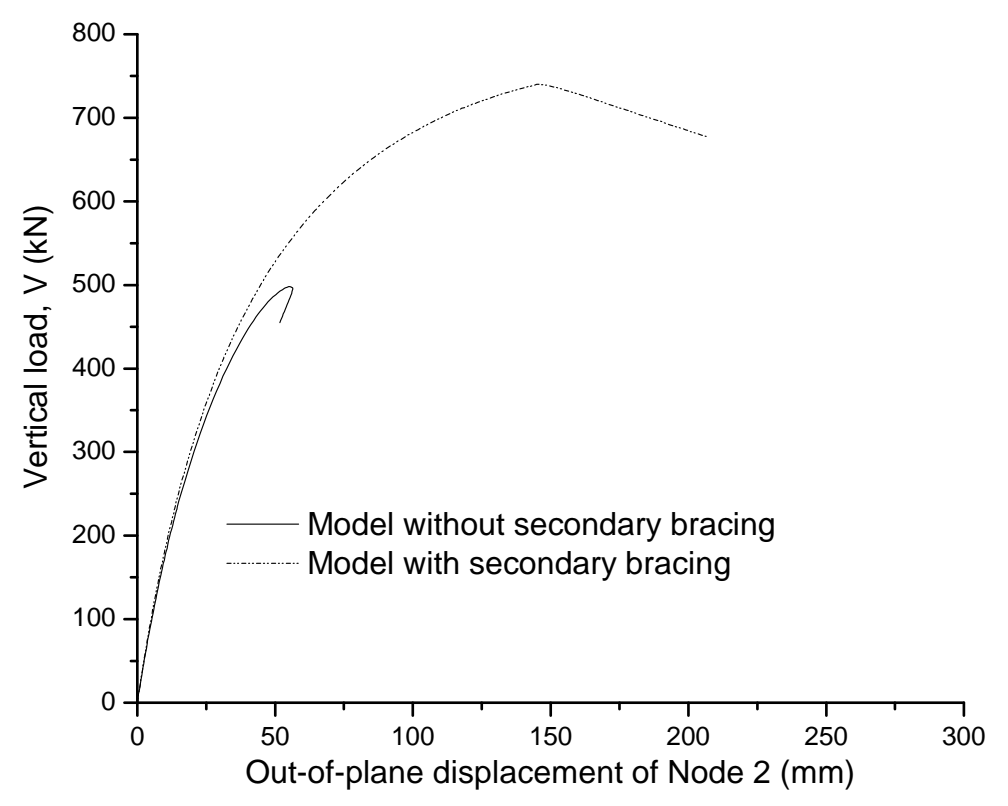

Figure 16. Load-deflection Curves of Rigid-connected Models under Vertical Load

The normalized stress $\left(\sigma / \sigma_{y}\right)$ in the secondary braces at the buckling capacity ranges from -0.017 to +0.019 in the horizontal load case and from -0.055 to +0.082 in the vertical load case. It can be seen that the axial stresses for the secondary braces are small. These results indicate that secondary braces prevent large displacements by reducing the effective length of the main members and thus enhance the buckling capacity. As a result, secondary braces should not be neglected in the calculation of ultimate load even though the axial stress on them is small.

\subsection{Effect of the Free Edge Direction of Angle Braces}

In an analysis of the angle truss model of reference 5, the SS configuration (free edge on the same side) has a greater ultimate load capacity than that of the OS configuration (free edges on opposite sides). Here, the effect of the free edge direction of the main braces is studied. The tower panel with secondary braces is studied with different free edge directions of the main braces, as shown in Figure 17.

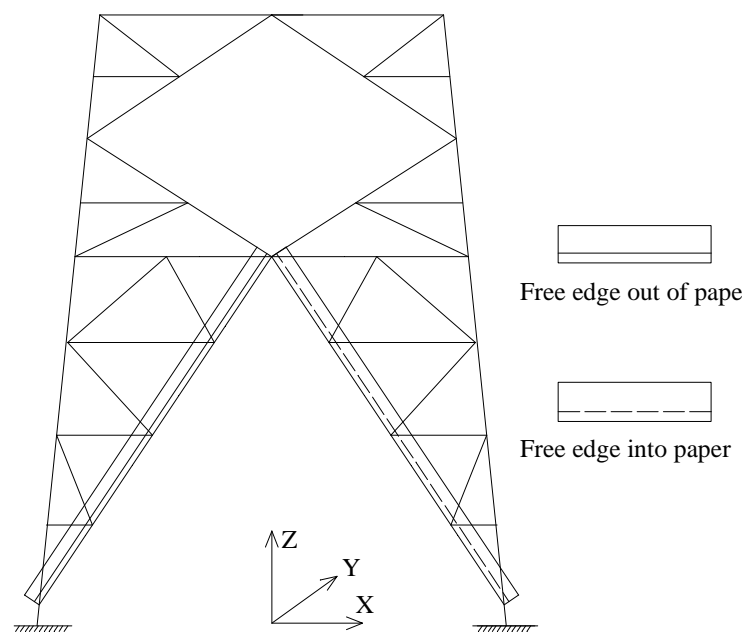

a) Opposite Side Model

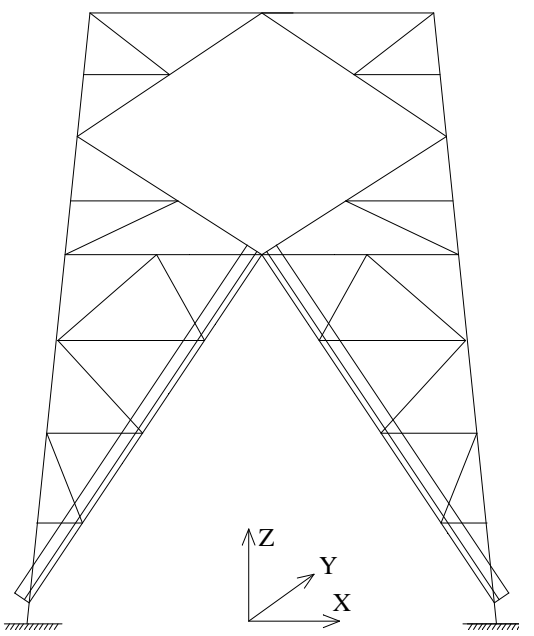

b) Same Side Model

Figure 17. Analysis Models with Different Free Edge Directions of the Main Braces 
Due to the difference in angle directions, the failure mode is caused by the excessive bending of the leg member, as shown in Figure 18. When this failure mode is compared to the one in Figure 10 (for SS configuration), the bending directions of the failed member in the two models are different.

The calculated out-of-plane displacement of node 2 (as indicated in Figure 6) for both the OS and SS configurations under horizontal and vertical loads are shown in Figures 19 and 20, respectively. As shown in the two figures, the leg free edge direction has significant effects under horizontal load, but has a very small effect under vertical load. Furthermore, the SS configuration performs better than the OS configuration, which happens to be very popular in transmission tower construction.

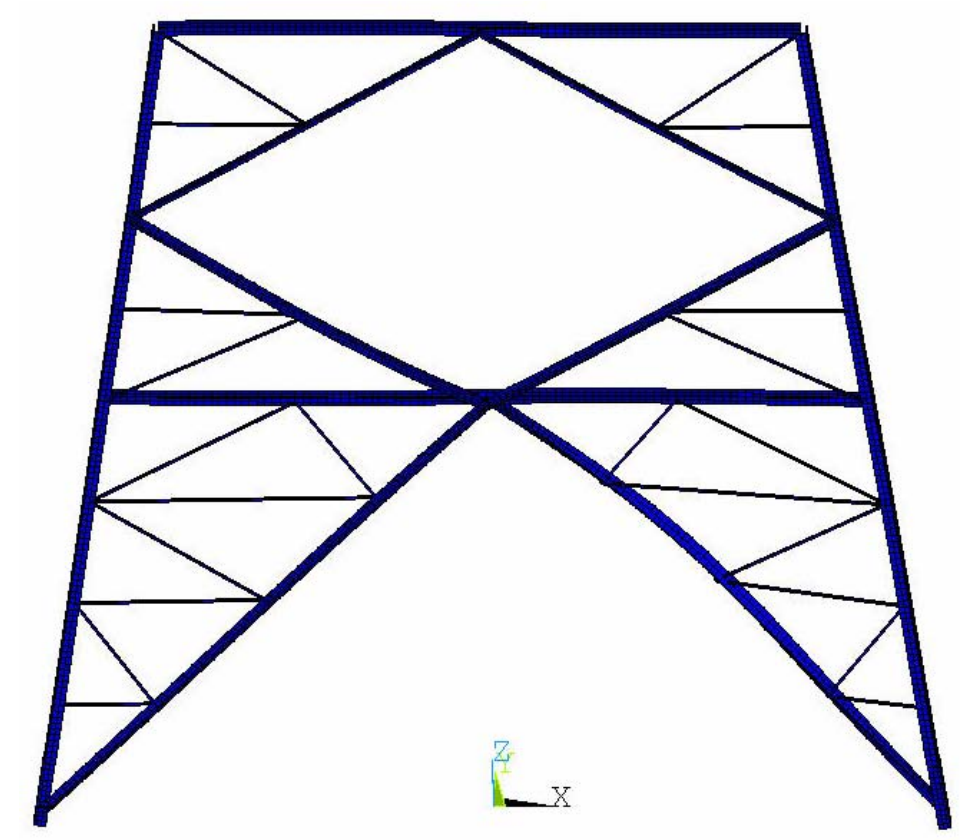

Figure 18. Failure Mode of Rigid Model with OS Configuration under Horizontal Load

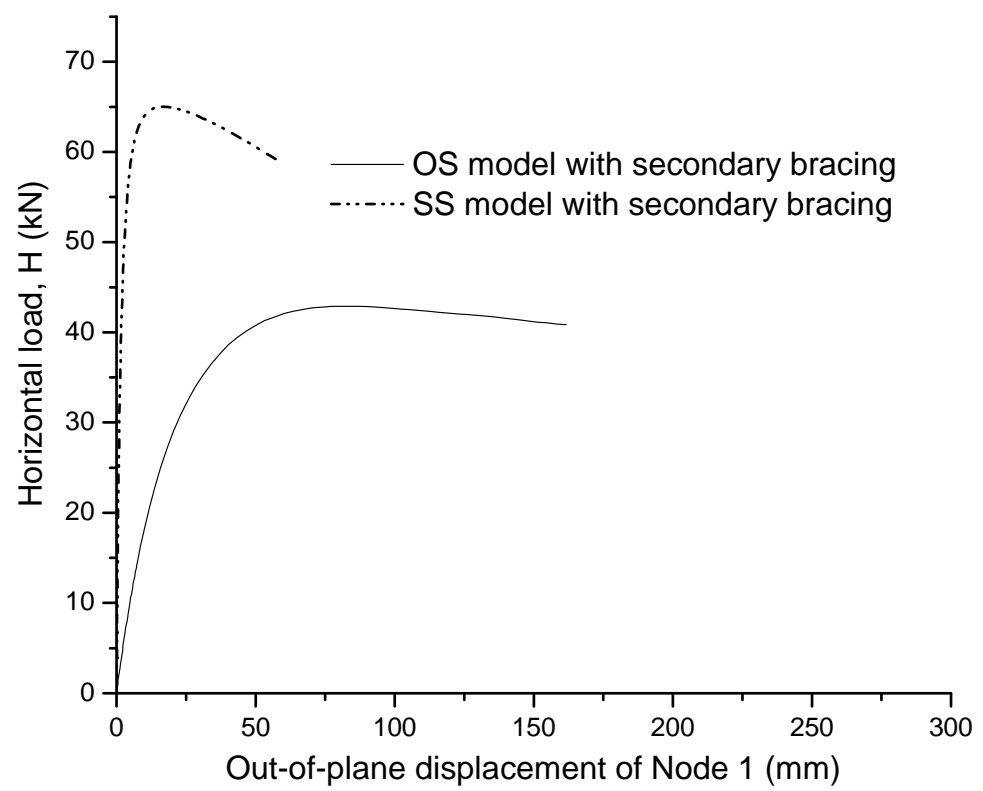

Figure 19. Load-deflection Curves of Node 2 with Secondary Bracing under Horizontal Load 


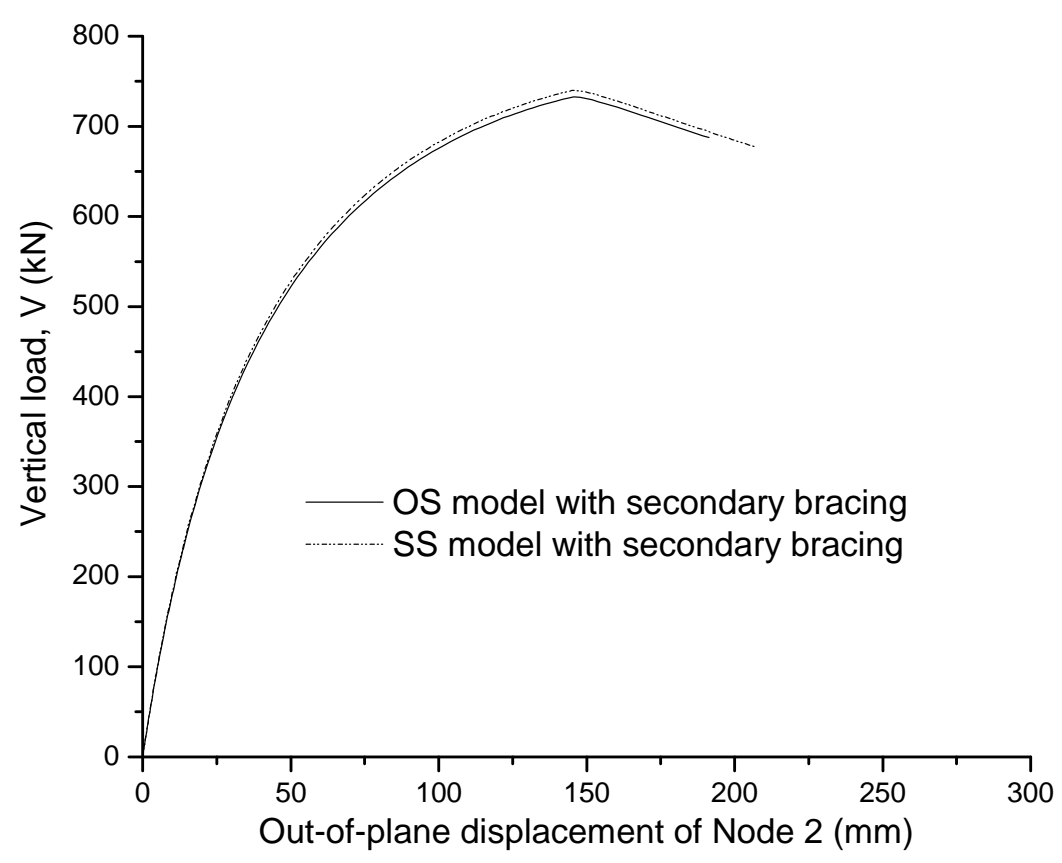

Figure 20. Load-deflection Curves of Node 2 with Secondary Bracing under Vertical Load

\subsection{Effects of Secondary Bracing Configurations}

Here, the effects of various secondary bracing configurations on buckling capacity are studied. Five secondary bracing configurations, as shown in Figure 21, are considered in this study. The SS configuration with rigid connections is employed in all of the models in Figure 21.

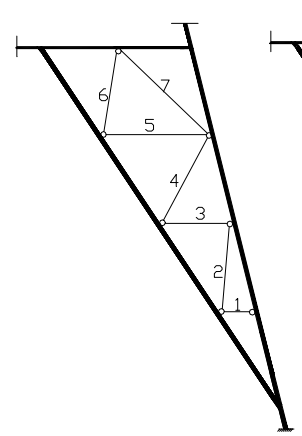

(A)

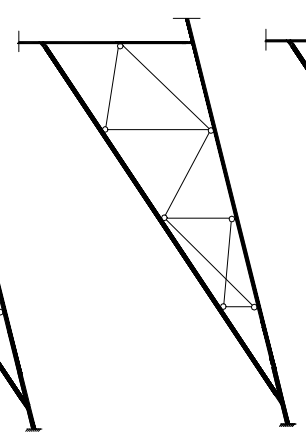

(B)

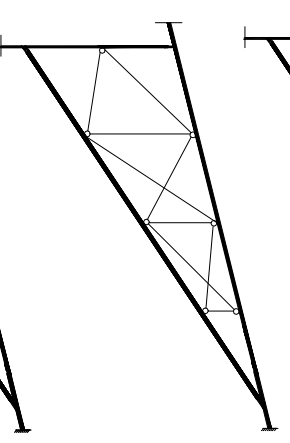

(C)

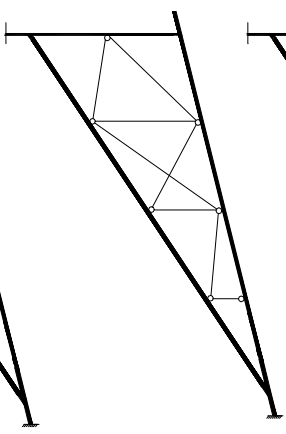

(D)

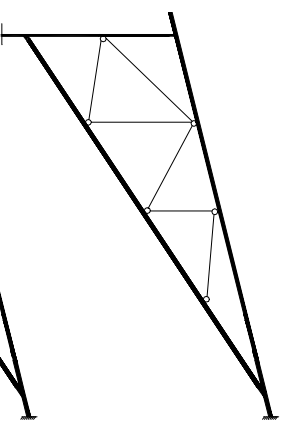

(E)

Figure 21. Secondary Bracing Configurations 


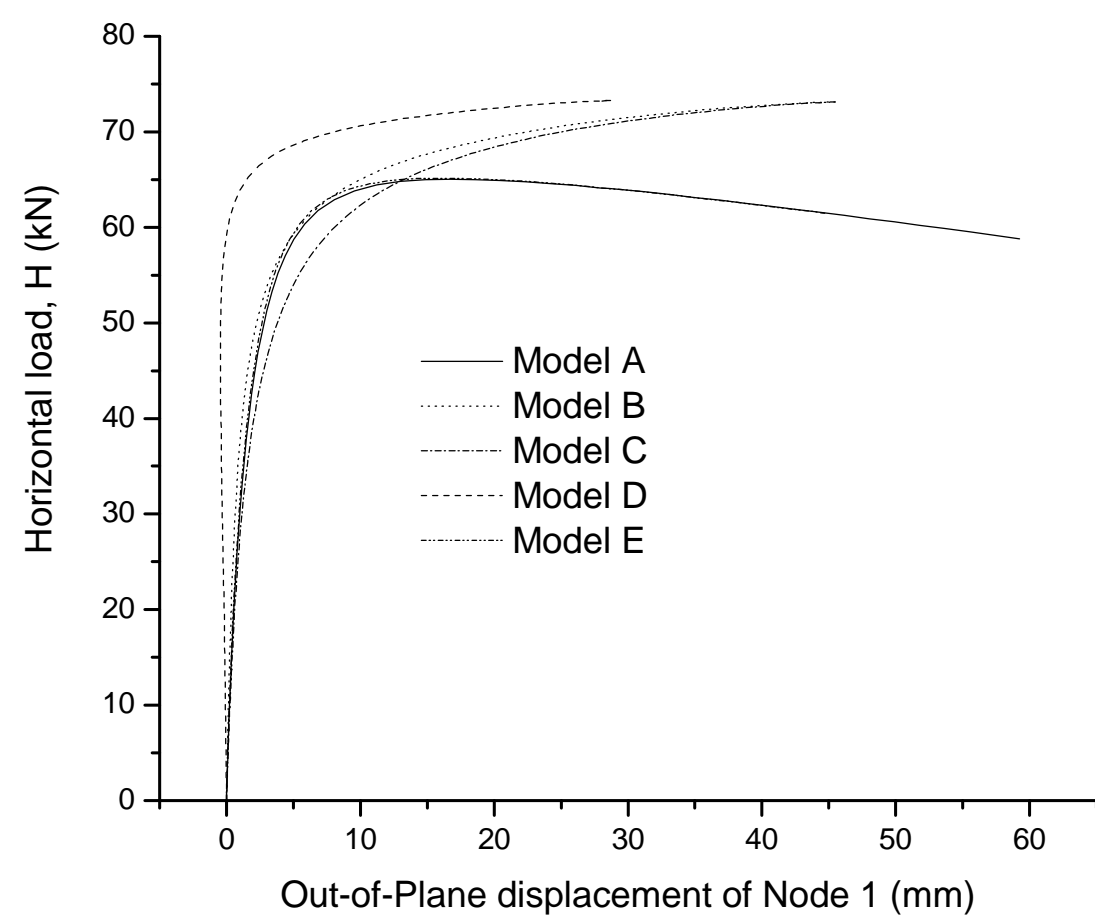

Figure 22. Load-deflection Curves of Models under Horizontal Load

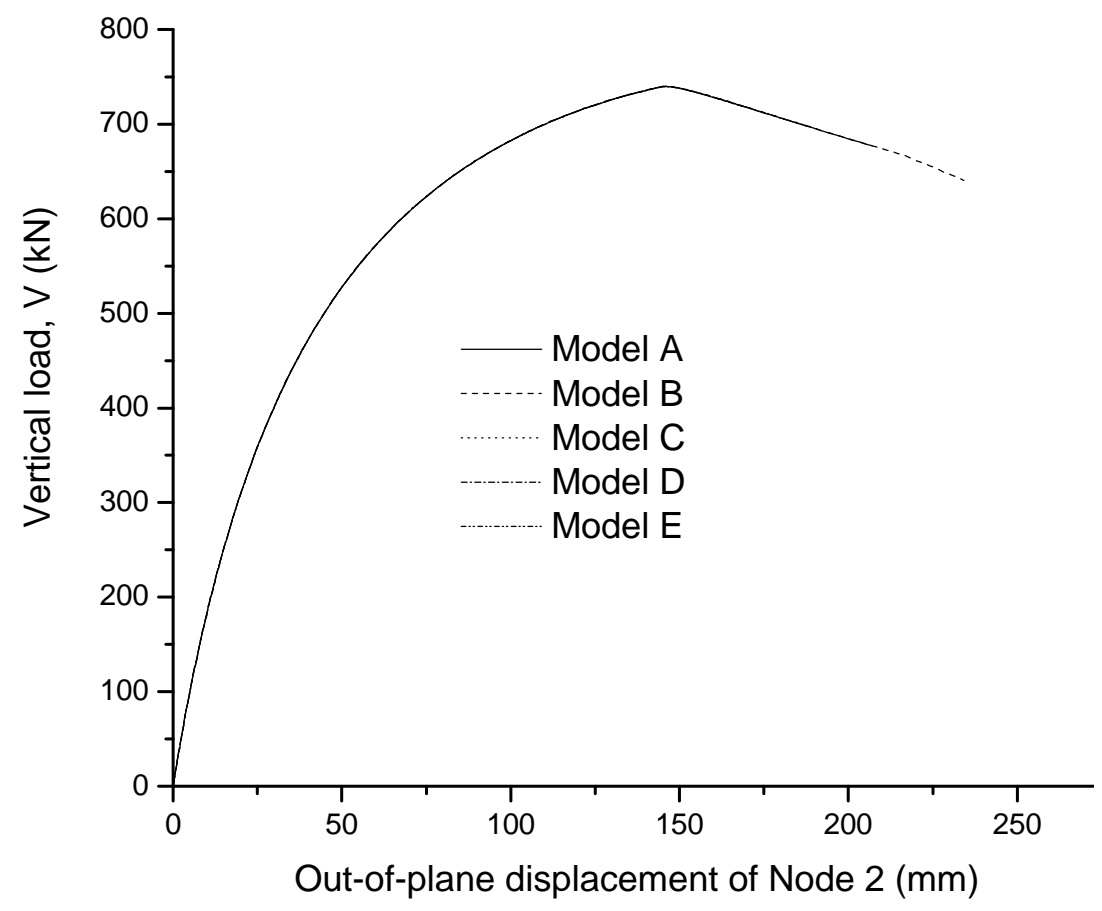

Figure 23. Load-deflection Curves of Models under Vertical Load

The failure modes of the five models are the same as those that are given in Figure 10 (under horizontal load) and Figure 11 (under vertical load). Figure 22 shows that the load-deflection curves for the models under horizontal load are very sensitive to the secondary bracing configurations. Models B, C, and D have relatively higher ultimate load capacities than do Models A and E. This can be attributed to cross bracing in Models B, C, and D, because cross bracing can help to enhance rigidity. Furthermore, the ultimate load capacities of Models B, C, and D are very close to each other. Hence, it can be concluded that all of the forms of cross bracing have similar effects on the ultimate load capacity. Figure 23 shows that the load-deflection curves for different 
models under vertical load are almost the same. This is because buckling under vertical load is induced by the horizontal members, whereas buckling under horizontal load is induced by the leg members, for which the secondary braces make a significant contribution to the behavior of the system.

\section{CONCLUDING REMARKS}

A finite element model (FEM), which considers member continuity, asymmetrical sectional properties, the eccentricity of connections, and geometrical and material nonlinearities, is proposed and was verified by experimental data from the literature [5]. A series of comprehensive parametric studies were then carried out with the proposed FEM. Referring to the results of the analysis, the following conclusions are made.

1. The connection rigidity of the main braces should be considered when calculating the ultimate load capacity of a tower, as it has significant effects on the buckling capacity of the overall structural system. Inappropriate modeling of the connection rigidity may overestimate or underestimate buckling capacity.

2. Although secondary braces are usually subjected to very small axial loads, the results show that their existence greatly enhances the buckling capacity of the structure by reducing the effective length of the leg members. Nonlinear analysis without consideration of secondary braces may lead to an unreliable prediction of the ultimate load capacity of the system.

3. The free edge direction of the main braces has significant effects on the buckling capacity of transmission towers in certain cases. The SS configuration performed better than the OS configuration did in the example that was used in this paper. In a calculation of the ultimate load capacity of transmission towers, a consideration of the effect of free edge directions in the FEM is strongly recommended.

4. The results of the analysis also show that cross bracing in the secondary bracing configuration can enhance the ultimate load capacity of the structure. Furthermore, the case study also shows that different types of cross bracing configurations provide a similar enhancement of buckling capacity.

\section{REFERENCES}

[1] Marjerrison, M., "Electric Transmission Tower Design,” Journal of the Power Division, ASCE, 1968, Vol. 94(PO1), pp. 1-23.

[2] British Standards Institution, "BS8100: Part 3. Lattice Towers and Masts: Code of Practice for Strength Assessment of Members of Lattice Towers and Masts,” 1999, London, UK.

[3] American Society of Civil Engineers, "ASCE 10-97: Design of Latticed Steel Transmission Structures," 1998, New York, USA.

[4] Cannon, D.D.J., "Variation in Design Practice for Lattice Towers," Proceedings of the Sessions related to Steel Structures at Structures Congress of ASCE, San Francisco, CA, USA, 1989, pp. 268-277.

[5] Kitipornchai, S., Albermani, F.G.A. and Chan, S.L., "Elasto-plastic Finite Element Models for Angle Steel Frames,” Journal of Structural Engineering, ASCE, 1990, Vol. 116, No. 10, pp. 2567-2581.

[6] Albermani, F.G.A. and Kitipornchai, S., "Non-linear Analysis of Transmission Towers", Engineering Structures, 1992, Vol. 14, No. 3, pp. 139-151.

[7] Roy, S., Fang, S.J. and Rossow, E.C., "Secondary Stresses on Transmission Tower Structures,” Journal of Energy Engineering, 1984, Vol. 110, No. 2, pp. 157-174. 
[8] Korol, R.M., Rutenberg, A. and Bagnariol, D., "On Primary and Secondary Stresses in Triangulated Trusses,” Journal of Constructional Steel Research, 1986, Vol. 6, No. 2, pp. 123-142.

[9] Rao, N.P. and Kalyanaraman, V., "Non-linear Behaviour of Lattice Panel of Angle Towers”, Journal of Constructional Steel Research, 2001, Vol. 57, No. 12, pp. 1337-1357.

[10] Knight, G.M.S. and Santhakumar, A.R., "Joint Effects on Behavior of Transmission Towers," Journal of Structural Engineering, ASCE, 1993, Vol. 119, No. 3, pp. 698-712.

[11] Kemp, A.R. and Behncke, R.H., "Behavior of Cross-bracing in Latticed Towers," Journal of Structural Engineering, ASCE, 1998, Vol. 124, No. 4, pp. 360-367.

[12] Robert, V. and Lemelin, D.R., "Flexural Considerations in Steel Transmission Tower Design," Proceedings of the "Electrical Transmission in a New Age" Conference of ASCE, Omaha, Nebraska, USA, 2002, pp. 148-155.

[13] ANSYS Inc., ANSYS Structural Analysis Guide. 